\title{
EXPERIMENT D' - SERIOUS GAME FOR THE DEVELOPMENT OF INTERCULTURAL COMPETENCES. CONCEPT, CONTENT, AND EXPERIENCES
}

\author{
Gala Rebane ${ }^{1}$, \& Maik Arnold ${ }^{2}$ \\ ${ }^{I}$ Chemnitz University of Technology, Faculty of Philosophy (Germany) \\ ${ }^{2}$ Fachhochschule Dresden - University of Applied Science, Faculty of Applied Social Sciences (Germany)
}

\begin{abstract}
The paper presents an intercultural serious game 'Experiment D', which was developed in a cooperation between the junior professor of Intercultural Competence (Chemnitz University of Technology) and the chair of Social Work Management (FHD Dresden - University of Applied Sciences). The game was successfully tested and assessed in the summer term 2017 and 2018. The main plot consists of a communicative negotiation and strategic handling of a complex situation at university that involves various stakeholders, both within and without it. The game fosters cultural awareness and self-reflection, appreciation of and a creative approach towards diversity, as well as general communicative, social, and team competences. Since it does not require any specialised prior knowledge, 'Experiment D' potentially addresses students of all disciplines. The participants of the two test sessions were students of the study fields MERGE Technologies for Resource Efficiency (study component "Soft Skills", Faculty of Mechanical Engineering) and Intercultural Communication and Competence (compulsory study component Intercultural Learning, Faculty of Humanities) at the Chemnitz University of Technology. Ethnicity, nationality, first language(s), degree of proficiency in English and German, and academic background were all factors that engendered a highly diverse game setting. Aside from the concept of the game, as well as its methodology and didactics, the paper also discusses the results of its assessment.
\end{abstract}

Keywords: Diversity, interculturality, intercultural competence, intercultural learning, serious games.

\section{Serious games in cross-cultural learning}

Nowadays, serious games are an acknowledged didactic instrument in higher education mostly used in business and technical study courses as a means of furthering soft skills (cf. Hoeborn 2016; Strohschneider 2010). Their specific potential for intercultural learning is also increasingly exploited. Intercultural competence is regarded as a "key competence of the $21^{\text {st }}$ century" and has therefore become a normative precept in educational politics (cf. Straub 2007). Most definitions of intercultural competence include social, communicative, and performative competences that could be acquired and trained in serious games (see Bolten 2006 for a conceptual differentiation between general and intercultural performative competence). Complexity, dynamism, non-transparency, uncertainty in the processes of decision-making, and a relative freedom of action on the part of their participants are the common properties of all serious games. Other chief elements of simulation include time pressure, role conflicts and conflicts of interest. In contrast to those serious games where an increase in intercultural competence is conceived as a mere side effect of a promotion of general communicative and social competences as well as leadership and decision-making skills, the main learning objective of intercultural simulation games is an enhancement of cultural and intercultural expertise. Digital communication technologies are ushering in new possibilities of creating immersive learning environments in which intercultural encounters and interactions can be simulated in a realistic manner, while students also practice their 'digital skills' (cf. e.g. Lane / Hays 2008; Strohschneider 2010).

On the whole, intercultural simulations and serious games ground on either a culture-general or a culture-specific approach (Landis / Bhagat 1996) that underlie their conception. There are three principal strategies of integrating intercultural aspects into the game context. First, it can be achieved through direct interculturality when various (real or fictitious) 'cultures' are embedded in the game concept as its integral element, and the respective 'cultural scripts' are set by the game rules. Examples of such games include, for instance, Modis \& Trados (Flechsig 2007), InterAct (Bolten 2002) and Globelia (research 
group "Social Competences" of Chemnitz University of Technology, no date). Second, interculturality may also emerge from the participants' linguistic and cultural diversity and therefore be of indirect nature; such is the case of the serious game Atlanticon (Stumpf et al. 2003). Finally, there is also the option of implicit interculturality, whereby misunderstandings and conflicts do not solely or necessarily arise from cultural-as-ethnic differences of players but are, rather, a result of both conflictual role interests and an unequal distribution of power and resources which are predetermined by the game design (cf. Strohschneider 2010:250). It is this form of interculturality the serious game Experiment $D$ draws on. However, indirect interculturality played a likewise vital role in its practical implementation in heterogeneous student groups and afforded an additional layer of complexity. In what follows, we shall present and discuss the conceptual framework, methods, and didactics of Experiment $D$ as well as some central results of its assessment.

\section{The serious game Experiment D}

\subsection{Outset and objectives}

The serious game Experiment $D$ was developed in cooperation between Assistant Professor for Intercultural Competence (Chemnitz University of Technology) and Chair for Social Management (Dresden University of Applied Sciences) within the framework of the seminar "Cross-Cultural Learning" at Chemnitz University. Since it requires no specialised knowledge, the game targets students of all disciplines. In particular, students of Intercultural Communication / Competence (compulsory module Cross-Cultural Learning, Faculty of Humanities, Chemnitz University of Technology) as well as students of the research cluster MERGE Technologies for Resource Efficiency" (optional module Soft Skills, Faculty of Mechanical Engineering, Chemnitz University of Technology) were actively involved in its conception, development, practical implementation and assessment. The strongly pronounced heterogeneity of the group was also used as a vital intercultural game resource. Due to the varying expectations, disciplinary cultures, levels of language proficiency, ethnic/national backgrounds, and other differences between the participants, the learning settings were marked by a high degree of ingrained diversity. The main objectives of the game were sensitisation for interculturality, initiation of cultural (self-)reflection, promotion of constructive and creative strategies in dealing with (cultural) differences as well as acquisition and development of cross-disciplinary key competences (soft or, else, transferrable skills).

The intercultural serious game Experiment $D$ has several unique features. Firstly, its design does not involve any direct intercultural aspects. By this token, it critically distances itself from a static concept of culture (concept of culture as a 'system' or a 'set of rules'), which underlies many other intercultural serious and role games. Instead, the game prioritises the performative aspects of culture (the concept of 'doing culture'). With our long-term professional experiences as intercultural trainers in mind, we wanted to make the task of 'learning' their respective roles easier for the participants, for even in very simple role exercises, it is hardly possible to expect students to get into the spirit of a randomly assigned and unfamiliar role at short notice, let alone act on it effortlessly. Therefore, differences were generated, secondly, by harnessing role conflicts and conflicts of interest on one hand, individual differences concerning language, socialisation, academic disciplines, and expectations on the other. This secured an alienating potential of specific gaming situations, which was imperative for the striven-for cultural (self-) reflection. Thirdly, acquisition of intercultural competence fundamentally requires intercultural learning receptivity as a voluntary and creative involvement with the unfamiliar. In order to prompt all students to meet this challenge regardless of their cultural background and assigned role, the Other is introduced into the game both as the trigger of the onset conflict and the central object of discussions. What is more, it is an unfathomable, untransparent, and estranging Other, in dealing with which students cannot draw on any real-world interpretative frameworks and solution strategies, nor are they restrained by any pre-existing behavioural patterns: the 'Object D' is a dragon accidentally cloned in the course of a biogenetic experiment at Sonnenstadt University. This circumstance requests students to leave their comfort zone and deploy their creative potential. Relation to reality was, however, maintained by means of situating the game scenario at university as a context relatively well-known to all participants. The introduction of a blatantly fictitious object of controversy ensured that no participants have qualms about involuntarily slighting an actually existing group of people, which, in turn, resulted in a wider variety of options for individual and collective action. At the same time, it also allowed focusing on ethical concerns that are often left out of consideration in intercultural trainings. Ethical issues were raised and critically discussed in the debriefing phases. 


\subsection{Contents, actors, and course of the game}

Main content of the game consists in a negotiation of, and coping with, a complex emergency situation at a university/college that involves communication with various stakeholders both with and without the organisation itself. At the onset, the participants were presented with the following story:

At a university in a medium-sized town, a dragon ('Object D') was cloned as a side product of a bioengineering experiment. The available third-party funds, which may otherwise have been used for its study, are nearly exhausted and the subsequent funding application has been turned down due to an interference of the Ethics Council. The university innovation budget would likewise not suffice to conduct further research on this unprecedented phenomenon. Both the scientists and the university administration are, however, interested in the resumption of the experiment and are currently looking for alternative funding options. Representatives of industry try to seize the opportunity and approach them with various offers. Furthermore, two influential local initiatives, the action group FEDORA (For Environment, Democratic Opportunities and Realistic Approaches) as well as the animal protection society Cloud Nine, are vehemently protesting against the experiment, although on different grounds. The mayor is running for re-election and is therefore trying to mediate between the parties: it is the university that provides most workplaces for the local community that has hard time dealing with high rates of unemployment, detrimental state of many buildings and vacant premises in the town centre. In the course of the game, all actors should attempt to work out a satisfactory solution for the crisis in accordance with their respective functional roles.

Roles in the game include members of the university administration (President, Chancellor, PR Manager), researchers (Head of the Department, Head of the Laboratory, further scientific staff), local authorities (Mayor, Mayor's Aide), representatives of FEDORA and Cloud Nine as well as deputies of the industrial corporations Ignis Bio and Lux.

In summer terms 2017 and 2018, the game was tested out in the course of five 90-minute-long sessions. Each of those included the phases of briefing, intervention, and debriefing. The first session started with an introduction to the game concept and narrative by the facilitators, after which individual roles were assigned and the preliminary strategic brainstorming within separate action groups took place. The second session encompassed three parallel discussion rounds between different stakeholders. The third session consisted of two parallel discussion rounds in larger stakeholder groups. In the fourth session, all participants met at a round table for the final negotiation. Each session began with a briefing and closed with a debriefing. In the fifth and final game session, the participants discussed the game experience and outcomes and were instructed in written self-reflection.

The game process was facilitated by the use of the Learning Management System OPAL, which enabled individual actors and stakeholder groups to maintain active asynchronous contact between separate sessions. The game could not, however, be fully converted to a digital format. Aside from OPAL, students both engaged in face-to-face interactions and exchanged information and relevant materials (e.g., open letters and press releases) via private communication channels such as WhatsApp, SMS, and e-mail. Between the first and the second session, the facilitators also published a controversial newspaper article on OPAL in order to additionally stimulate the game dynamic.

During the whole game, the following rules of communication applied: (1) each role had to be performed with its functional description in mind; (2) everyone was free to communicate with other people und groups; (3) language(s) of communication could be chosen freely; (4) participants were free to use any analogue or digital channels of communication for exchange of information, campaigning and public relations activities; (5) the participants had to abide by the game agenda and the time plan; (6) all agents and stakeholder groups were expected to develop and pursue their own strategy; their respective goals had to be attained up to $80 \%$ at least.

\section{Assessment of the serious game Experiment D: Discussion and reflection}

The game has so far been tested in four groups (Group A: 2017; Groups B and C: 2018; Group D: $2017^{1}$ ), which ranged significantly in terms of their size and acceptance of the game. Groups A and B (ca. 15 participants each) showed high levels of acceptance and participated actively. They also stood out with regard to their creativity in task accomplishment. In contrast, Group C (ca. 30 participants) displayed much lower levels of acceptance, and Group D (8 participants) scored the lowest. Language diversity of the participants was particularly strong in Groups B and C. In those, main challenge was, admittedly, of

\footnotetext{
${ }^{1}$ In contrast to groups A, B, and C, which encompassed students of intercultural communication and competence as well as students of mechanical engineering (MERGE), group D consisted of non-academic staff of Dresden Technical University, at which we run the game in 2017 as a one-time offer in SprInt programme.
} 
communicative (although not exclusively language-related) nature. Group C, and even more so Group D had major difficulties with getting into the spirit of the assigned roles and/or enacting them strategically. The gaming experience was assessed with the help of (1) oral questions for consideration both during the debriefing phases and in the framework of the final plenary discussion; (2) individual written reports submitted at the end of the term. The latter were subsequently subjected to qualitative content analysis (Glaser / Strauss 1967) by the facilitators. The main findings are presented below.

(i) Culture concept: With regard to communication, the participants stressed the fact that integrated references to university culture - even though they may not have possessed full knowledge of its particulars - enabled them to better identify with the game on the whole. Due to the individual differences in national and disciplinary background, the groups viewed themselves as heterogeneous. Acquisition of intercultural experiences was supported by the variation in tasks and group constellations. The participants put emphasis on their practically relevant understanding of culture that could neither be reduced to the concept of 'national cultures' nor to an idea of static system of differences. Instead, they perceived culture as both a dynamic process of negotiation and an expression of collective and individual agency that also entails controversy and power struggles. It was thus possible to critically challenge a utopian vision of interculturality as a peaceful coexistence and focus instead on its practical challenges.

(ii) Communication patterns and language issues: In the course of the game, students learned to know and embrace different styles and patterns or communication (e.g. communicative conventions of expressing one's opinion, reaction to criticism in plenum debates). Use of English as language of conversation (lingua franca) was generally perceived as an ambivalent challenge. Aside from requiring good improvisation skills, could in some cases hinder an in-depth exchange, lead to communicative difficulties and misunderstandings, and restrain display of personal rhetorical abilities.

(iii) Cognitive patterns and solving strategies: The game sessions made visible different approaches to problem solving such as, for instance, pre-planned vs. spontaneous and episodic vs. continuous strategies. The participants described their awareness, appropriation, and modification of different patterns of problem solving as a positive learning effect. The continual debriefings helped them to apprehend their respective experiences so that the gained insights could be fruitfully translated into future action.

(iv) Stress management and adjustment skills: With regard to the degree of personal involvement, the participants' perception of the game also varied. Some of them voiced their insecurity and stress caused by its complexity and dynamic character. However, phases of indecision gave way to phases of goal-driven further development in teams. The participants emphasised the necessity of active stress reduction in unclear situations that would make possible further collaboration with other people even if those might not share one's own values and convictions. This specific experience was also likened to the experiences previously made in the course of a term/traineeship abroad.

(v) Stereotypes and prejudice: Both consciously and unconsciously as well as deliberately and unintentionally, various stereotypes and prejudiced attitudes - such as sexist, racist, or otherwise disparaging comments directed at the members of outgroups - were reproduced in the course of the game. Their negative impact on the group dynamic in teams was nonetheless swiftly recognised and critically discussed.

(vi) Leadership skills: Students reported to have watched internet videos in the timespan of the game in order to optimise their respective role performance. They also appreciated the opportunity to try out their 'hidden leadership qualities' during the game on a trial-and-error principle. Furthermore, they also expressed the view that in future, those skills and abilities should be targeted in the curricula in a more comprehensive manner. They also reported that by assuming leadership in the game they had discovered new facets of their personality that needed further honing (e.g. active listening skills, empathy).

\section{Didactic considerations and conclusions}

With regard to the game implementation, both the participants and the facilitators made the following observations that are of relevance for future development of intercultural serious games:

(i) Impact of setting and context: In the course of the game, it became apparent that external circumstances have a significant impact on its structure, process and outcome. In some cases, introduction to the game, separate gaming sessions and debriefing required more time than planned. In larger groups that generally allowed for more communication, communicative processes tended to grow less straightforward. Physical settings predetermined by the respective infrastructure (too little space in the classroom, high noise levels, use of technical appliances) were also among the factors that influenced the game. 
(ii) Immanent deficits of the game and possible solutions: In nearly all groups, the debriefing phases showed the necessity of even greater detail in role descriptions and individual briefings. It also became apparent that in different stages of the game, it would be necessary to encourage consensus building and compromising on the part of the decision makers (e.g. by providing more detailed information about the respective budgets of industry partners, the upcoming mayor election, and the attractive offers of internationally renowned research institutions) while taking into consideration possible limitations which different functional roles put on the individual freedom of action. Furthermore, an introduction of a score system for separate goal achievements would also boost up the overall play motivation.

(iii) Intercultural learning didactics: The serious game warranted a topical examination of interculturality and enhanced the students' sensibility towards plural and dynamic concepts of culture. Due to the different backgrounds of the participants, it helped to bring home diversity in the sense of implicit and indirect interculturality without having to directly stipulate cultural differences in role descriptions. The game promoted transdisciplinary intercultural, communicative, and social skills, prompted the use of German or, else, English as foreign language and furthered active strategies of stress management in dealing with communicative misunderstandings. Moreover, it enabled the participants to practise, and deliberate on, such central interpersonal competences as frustration tolerance, empathy, and the ability to change perspective. As a format predicated on experimental and problem-oriented learning, the game allowed gathering practical experience in a sheltered environment, experimenting with new patterns of behaviour and enhancing personal performative potential with the help of new self-knowledge. It is our conviction that in future, intercultural serious games should be given primary consideration both in the framework of internationalisation of study programmes and in didactics of higher education.

\section{References}

AG Soziale Kompetenzen, Technische Universität Chemnitz (n.d.). Globelia (Interkulturelles Planspiel).

Bolten, J. (2002). InterAct (Medienkombination): interkulturelles Verhandlungstraining/Intercultural negotiation training. Wissenschaft und Praxis. Sternenfels.

Bolten, J. (2006). Interkulturelles Lernen mit Multimedia gestalten. In: Hohenstein, Andreas und Wilbers, Karl (Hrsg.) Handbuch e-Learning. Expertenwissen aus Wissenschaft und Praxis - Strategien, Instrumente, Fallstudien. 16. Jg. Fachverlag Wirtschaftsdienst. Köln, o.S.

Flechsig, K.-H. (2007). Modis und Trados (Interkulturelles Planspiel).

Glaser, B.G. und Strauss, A.L. (1967). The Discovery of Grounded Theory. Strategies for Qualitative Research. New York: Aldine.

Hoeborn, G. (2016). Serious games in engineering higher education. In: Proceedings of the $19^{\text {th }}$ Verona Toulon International Conference Excellence in Services. URL: http://sites.les.univr.it/eisic/wpcontent/uploads/2018/07/Hoeborn-serious-games.pdf [Zugriff am 11.10.2020].

Landis, D. \& Bhagat, R.S. (Hrsg.). Handbook of Intercultural Training. $2^{\text {nd }}$ ed. London, New Delhi: Sage.

Lane, H.C. \& Hays, M.J. (2008). Getting Down to Business: Teaching Cross-Cultural Social Interaction Skills in a Serious Game. In: Blanchard, Emmanuel und Allard, Danièle (Hrsg.) CATS 2008: Workshop on Culturally-Aware Tutoring Systems. Proceedings. Montreal. URL: https://www.iro.umontreal.ca/ blanchae/CATS2008/CATS2008.pdf [Zugriff am 11.10.2020].

Straub, J. (2007). Kompetenz. In: Straub, Jürgen; Weidemann, Arne und Weidemann, Doris (Hrsg.) Handbuch interkulturelle Kommunikation und Kompetenz. Verlag J.B. Metzler. Stuttgart, Weimar, S. 35-46.

Strohschneider, S. (2010). Planspiele und Computersimulationen. In: Weidemann, A.; Straub, J., Nothnagel, S. (Hrsg.), Wie lehrt man interkulturelle Kompetenz? Theorien, Methoden und Praxis in der Hochschulausbildung. Transcript. Bielefeld, S. 241-264.

Stumpf, S., Michel, T., Sokolowski, M. \& Wenzl, A. (2003). Training interkultureller Kompetenz mit dem Verhaltensplanspiel Atlanticon. In: Wirtschaftspsychologie aktuell 2, 47-53. 